\title{
Nanoarchitectures in Management of Fungal Diseases: An Overview
}

\author{
Vijay Mishra ${ }^{1, *(\mathbb{D})}$, Manvendra Singh ${ }^{1,2}$, Yachana Mishra ${ }^{3}$, Nitin Charbe ${ }^{4}$, Pallavi Nayak ${ }^{1,5}$ (D) \\ Kalvatala Sudhakar ${ }^{1}{ }^{\mathbb{D}}$, Alaa A. A. Aljabali ${ }^{6}{ }^{\mathbb{D}}$, Seyed H. Shahcheraghi ${ }^{7}$, Hamid Bakshi ${ }^{8}(\mathbb{D}$, \\ Ángel Serrano-Aroca $9, *$ (D) and Murtaza M. Tambuwala ${ }^{8, *(D)}$
}

1 School of Pharmaceutical Sciences, Lovely Professional University, Phagwara 144411, India; manvendra8668@gmail.com (M.S.); pallavinayak97@gmail.com (P.N.); ckbhaipharma@gmail.com (K.S.)

2 Unichem Laboratories Limited, C31-32, Meerut Road Industrial Area, Ghaziabad 201003, India

3 Departments of Zoology, Shri Shakti Degree College, Sankhahari, Ghatampur 209206, India; yachanamishra@gmail.com

4 Irma Lerma Rangel College of Pharmacy, Texas A\&M Health Science Center, 1010 West Avenue B, MSC 131, Kingsville, TX 78363, USA; nitinunimi@gmail.com

5 Faculty of Pharmaceutical Sciences, PCTE Group of Institutes, Ludhiana 142021, India

6 Department of Pharmaceutics \& Pharmaceutical Technology, Yarmouk University, P.O. Box 566, Irbid 21163, Jordan; alaaj@yu.edu.jo

7 Infectious Diseases Research Center, Shahid Sadoughi Hospital, Shahid Sadoughi University of Medical Sciences, Yazd 8916978477, Iran; shahcheraghih@gmail.com

8 School of Pharmacy and Pharmaceutical Sciences, Ulster University, Coleraine BT52 1SA, UK; bakshi-h@ulster.ac.uk

9 Biomaterials and Bioengineering Lab, Centro de Investigación Traslacional San Alberto Magno, Universidad Católica de Valencia San Vicente Mártir, c/Guillem de Castro 94, 46001 Valencia, Spain

check for updates

Citation: Mishra, V.; Singh, M.; Mishra, Y.; Charbe, N.; Nayak, P.; Sudhakar, K.; Aljabali, A.A.A.; Shahcheraghi, S.H.; Bakshi, H.; Serrano-Aroca, Á.; et al.

Nanoarchitectures in Management of Fungal Diseases: An Overview. Appl. Sci. 2021, 11, 7119. https://doi.org/ 10.3390/app11157119

Academic Editor: Morgan Hamon

Received: 14 June 2021

Accepted: 28 July 2021

Published: 31 July 2021

Publisher's Note: MDPI stays neutral with regard to jurisdictional claims in published maps and institutional affiliations.

Copyright: (C) 2021 by the authors. Licensee MDPI, Basel, Switzerland. This article is an open access article distributed under the terms and conditions of the Creative Commons Attribution (CC BY) license (https:/ / creativecommons.org/licenses/by/ $4.0 /)$.
* Correspondence: vijaymishra2@gmail.com (V.M.); angel.serrano@ucv.es (Á.S.-A.); m.tambuwala@ulster.ac.uk (M.M.T.)

Abstract: Fungal infections, from mild itching to fatal infections, lead to chronic diseases and death. Antifungal agents have incorporated chemical compounds and natural products/phytoconstituents in the management of fungal diseases. In contrast to antibacterial research, novel antifungal drugs have progressed more swiftly because of their mild existence and negligible resistance of infections to antifungal bioactivities. Nanotechnology-based carriers have gained much attention due to their magnificent abilities. Nanoarchitectures have served as excellent carriers/drug delivery systems (DDS) for delivering antifungal drugs with improved antifungal activities, bioavailability, targeted action, and reduced cytotoxicity. This review outlines the different fungal diseases and their treatment strategies involving various nanocarrier-based techniques such as liposomes, transfersomes, ethosomes, transethosomes, niosomes, spanlastics, dendrimers, polymeric nanoparticles, polymer nanocomposites, metallic nanoparticles, carbon nanomaterials, and nanoemulsions, among other nanotechnological approaches.

Keywords: fungal infection; nanoarchitecture carriers; drug delivery; antifungal drugs

\section{Introduction}

Fungal disease is one of the invasive, serious, and systemic topical infections commonly seen in humans' mucous membrane, tissues, and skin. In skin diseases, Candidiasis is one of the most common fungal infections caused by Candida species [1]. Current studies have evaluated that the fungal infections (specifically those infected through Candida, Aspergillus, and Cryptococcus spp.) kill more than one million persons per year [2]. Around $20-25 \%$ of the human population are suffering from mycoses [3]. Many antifungal drugs used to treat topical infections show associated toxicity and decreased therapeutic outcomes [4]. The antifungal drugs administered through the skin in various conventional forms (gels or creams) may show redness of the skin, erythema, stinging, and burning sensation as side effects [5]. Consequently, different vesicular preparations have been 
discovered to treat various topical fungal infections [5]. Additionally, invasive fungal infections are major causes of death, particularly in patients with AIDS, myelodysplasia, leukaemia, aplastic anaemia, immunocompromised organ transplant recipients, neonates, and geriatrics [6]. Every year, the mortality rate due to invasive fungal infections is approximately 1.5 million [7].

Based on fungal moieties, cutaneous mycoses are categorized into dermatophytosis, candida infections, and mold infections [8,9]. The majority of fungal infections can be observed on the scalp, skin, vagina, mouth, feet, and fingers [10]. However, warm and wet conditions are favorable for the growth of fungi [11]. These microorganisms (tinea and candida) thrive on the skin, especially between the fingers, under the armpits, and between the thighs [12]. Angioinvasive fungal infections invade the blood vessels, which results in the significant mortality and morbidity of immunocompetent and immunocompromised patients [13]. This review summarizes the different fungal diseases, state-of-the-art currently available treatment strategies, and advances in developing nanocarriers for the management of fungal diseases.

\section{Fungal Diseases}

The fungal infections mainly include dermatophytosis, Athlete's foot, yeast infection (Candidiasis), Jock itch or Tinea cruris, and Ringworm or Tinea corporis.

\subsection{Dermatophytosis}

It originates from dermatophytes, keratinophilic fungi that can invade keratinized tissue (e.g., nails, hair, and skin). They also invade, infect, and persist in the stratum corneum and occasionally penetrate underneath the surface of the epidermis and its appendages. Based on the microscopic characteristics, dermatophytes are classified as Epidermophyton, Microsporum, and Trichophyton species. The Syzygiumjambos L. (Alston) species has traditional therapeutic action and treats dermatophytosis in Southeast Asia [14].

\subsection{Athlete's Foot}

It is also called Tinea pedisis, a familiar fungal infection that affects the foot area of the body. Generally, it relates to sports areas because the fungus propagates entirely in a warm and humid environment-for example, sports equipment, shoes, socks, locker rooms, and moist clothes [14].

\subsection{Yeast Infection (Candidiasis)}

In women, vaginal yeast infections are caused by Candida albicans. The hypertrophies of candida disrupt the usual steadiness of yeast and bacteria in the vaginal organ. Basically, Candida is the reason for fungal infections in the mouth and vaginal area. The vaginal aphthosis comprises feelings of tanginess, discomfort, and a hot sensation. Generally, oral aphthosis is a pale patch located on the tongue and observed in pediatrics [15].

\subsection{Jock Itch}

Jock itch (Tinea cruris), a fungal skin disease, survives in humid and warm temperatures. Therefore, it grows out of control on the inner thighs, buttocks, and groin. Jock itch spreads from direct interaction with an infected patient or fungus area [16]. Indocile infections are considered easy to treat, but tinea cruris is very difficult [17]. In jock itch, the groin area is infected, and elevated temperature, stinginess, and foul smell are the most prevalent symptoms. In contagious patients, the most common symptoms observed are red-colored patches and swelling.

\subsection{Ringworm}

Ringworm or Tinea corporis, a skin disease, also causes athlete's foot and jock itch [17]. Dermatophytes mainly cause this fungal infection. These ringworm patches are red, spherical, and irritating rashes. 


\section{Currently Available Treatment Strategies for Fungal Diseases}

The treatment of fungal diseases involves systemic and topical antifungal agents, depending on the type of fungal skin disease, infection area, and skin penetration. Topical treatment is the most common for all kinds of skin infections. The classes of antifungals approved for treating patients with invasive fungal infections (IFIs) are triazoles, polyenes, and echinocandins [18].

Historically, Fluconazole and Itraconazole, among other azole drugs (first-generation), started in the 19th century and showed a potent broad-spectrum action of the deoxycholate preparation with fewer side effects. Voriconazole, Posaconazole, and Isavuconazole (second-generation azole drugs) showed a prolonged spectrum of activity against filamentous fungi. Antifungal topical azole drugs treated Pityriasis versicol when applied in the form of solutions, sprays, creams, and shampoos [19]. The azoles exert their effect by inhibiting CYP-dependent C-14 n-demethylase, an enzyme involved in converting lanosterol to ergosterol. It leads to the depletion of ergosterol, the essential sterol of the fungal cell membrane, and, ultimately, compromises cell membrane integrity [18].

Amphotericin $\mathrm{B}(\mathrm{AmB})$, a polyene antifungal agent with a broad range of activity against yeasts and molds, targets ergosterol. AmB is effective against Cryptococcus neoformans, Candida spp., Aspergillus spp., and agents of mucormycosis. However, some fungi, including Candida lusitaniae, Aspergillus terreus, Trichosporon spp., Geotrichum spp., and Scedosporium spp., are resistant to AmB [19].

In the 20th century, the Echinocandins drugs (Mycafungin, Caspofungin, and Anidulafungin) offered significant activity against candida infections and were commercially available only in the parenteral form. Echinocandins are cyclic lipopeptides that work by interfering with fungal wall synthesis. In a noncompetitive manner, they inhibit the synthesis of Caspofungin and an essential constituent of the fungal cell wall [19]. In contrast, because there are no $\beta$-glucans or $\beta$-glucan synthases in humans, these agents are less toxic than other antifungals [20].

The synthesis of ergosterol is interfered with terbinafine. It shows fungicidal action. It is effective against dermatophytes such as Microsporum spp., Trichophyton spp., and Epidermophyton. Fungistatic flucytosine interferes with the synthesis of protein and DNA. It is a fluorinated pyrimidine analog that is active against Candida spp. It is used in combination with azole or AmB. Hepatotoxicity and thrombocytopenia are associated with high concentrations, i.e., $>100 \mathrm{mg} / \mathrm{mL}[19,20]$. Tolnaftate, an antifungal agent, is a synthetic thiocarbamate that is used to treat ringworm, athlete's foot, and jock itch [19].

A synthetic antifungal agent, Ciclopirox, is active against superficial mycoses, particularly Tinea versicolor. It acts by the chelation of trivalent cations $\left(\mathrm{Fe}^{3+}\right.$ and $\left.\mathrm{Al}^{3+}\right)$, inhibiting the metal-dependent enzymes and interrupting the transport of amino acids and nutrients. Amorolfine is used to treat onychomycosis. Orally active Griseofulvin is effective against dermatophytes [10].

Various antifungal drugs are used to treat tinea and cutaneous candidiasis infections (Table 1 and Figure 1) [1,21,22].

Table 1. Site-specific action of antifungal drugs $[1,21,22]$.

\begin{tabular}{|c|c|c|c|}
\hline Chemical Constituents & Antifungal Drugs & Mechanism of Action & Dosage Form \\
\hline Polyenes & Nystatin and amphotericin B (AmB) & $\begin{array}{l}\text { - } \quad \text { Membrane barrier function } \\
\text { Ergosterol biosynthesis }\end{array}$ & $\begin{array}{l}\text { AmB shows nephrotoxicity as an } \\
\text { important side effect, which has limited its } \\
\text { indiscriminate use. The amphotericin B } \\
\text { lipid complex (ABLC) and liposomal } \\
\text { amphotericin B (L-AmB) are available to } \\
\text { overcome this impasse. }\end{array}$ \\
\hline Morpholines & Amorolfine & $\begin{array}{l}\text { - } \quad \text { Isomerase and sterol reductase } \\
\text { Ergosterol biosynthesis }\end{array}$ & $\begin{array}{l}\text { Loceryl solution exhibits a short residence } \\
\text { time. Films and adhesive patches, owing to } \\
\text { their occlusive properties, enhance nail } \\
\text { hydration, which augments the diffusion } \\
\text { of permeating molecules by causing } \\
\text { distension of the keratin fibers. }\end{array}$ \\
\hline
\end{tabular}


Table 1. Cont.

\begin{tabular}{|c|c|c|c|}
\hline Chemical Constituents & Antifungal Drugs & Mechanism of Action & Dosage Form \\
\hline Heterocyclic Benzofuran & Griseofulvin & $\begin{array}{ll}- & \text { Sliding of microtubules } \\
- & \text { Fungal, mitotic apparatus }\end{array}$ & $\begin{array}{l}\text { The novel formulation of such } \\
\text { nanoaprticles can overcome the poor } \\
\text { solubility of the drug. }\end{array}$ \\
\hline Thiocarbamate & Tolnaftate & $\begin{array}{l}-\quad \text { Squalene epoxidase } \\
-\quad \text { Ergosterol biosynthesis }\end{array}$ & $\begin{array}{l}\text { Tolnaftate is available in an aerosol, cream, } \\
\text { and lotion. Aerosols cause mild, temporary } \\
\text { stinging, while creams and gels need } \\
\text { longer times for curing and decrease the } \\
\text { patient compliance because of their poor } \\
\text { penetration. So, there is a need for } \\
\text { nanodrug delivery to overcome } \\
\text { these problems. }\end{array}$ \\
\hline Azoles & $\begin{array}{l}\text { First-generation: Ketoconazole, } \\
\text { clotrimazole, econazole, bifonazole } \\
\text { Second-generation: Itraconazole, } \\
\text { fluconazole, posaconazole, } \\
\text { voriconazole, terconazole, } \\
\text { ravuconazole, isavuconazole and } \\
\text { albaconazole }\end{array}$ & $\begin{array}{l}\text { Inhibition of the fungal } \\
\text { cytochrome P450 (P450) from } \\
\text { family } 51 \text { (CYP51 or sterol } \\
14 \alpha \text {-demethylase) } \\
\text { Ergosterol biosynthesis }\end{array}$ & $\begin{array}{l}\text { First- and second-generation drugs are } \\
\text { available in the form of cream, ointment, } \\
\text { and lotion. These traditional dosage forms } \\
\text { have poor skin penetration. Novel } \\
\text { formulations can overcome the drawback } \\
\text { of poor absorption and penetration } \\
\text { of drugs. }\end{array}$ \\
\hline Allylamines & Naftifine and terbinafine & $\begin{array}{ll}- & \text { Squalene epoxidase } \\
- & \text { Ergosterol biosynthesis }\end{array}$ & $\begin{array}{l}\text { Terbinafine tablet has gastrointestinal side } \\
\text { effects and an alternative dosage form } \\
\text { using topical formulation with a nanodrug } \\
\text { delivery system. }\end{array}$ \\
\hline Echinocandins & $\begin{array}{l}\text { Caspofungin, Micafungin and } \\
\text { Anidulafungin }\end{array}$ & $\begin{array}{l}\text { - Inhibit the }(1,3)-\beta \text {-D-glucan } \\
\text { synthase }\end{array}$ & Intravenous injection. \\
\hline Antimetabolite & Fluocytosine & - Inhibit thymidylate synthetase & Used orally and intravenous injection. \\
\hline Hydroxypyridone derivative & Ciclopirox & $\begin{array}{l}\text { Inhibition of transport of amino } \\
\text { acids and nutrients }\end{array}$ & $\begin{array}{l}\text { Available as topical solution. Usually } \\
\text { applied once a day. }\end{array}$ \\
\hline
\end{tabular}

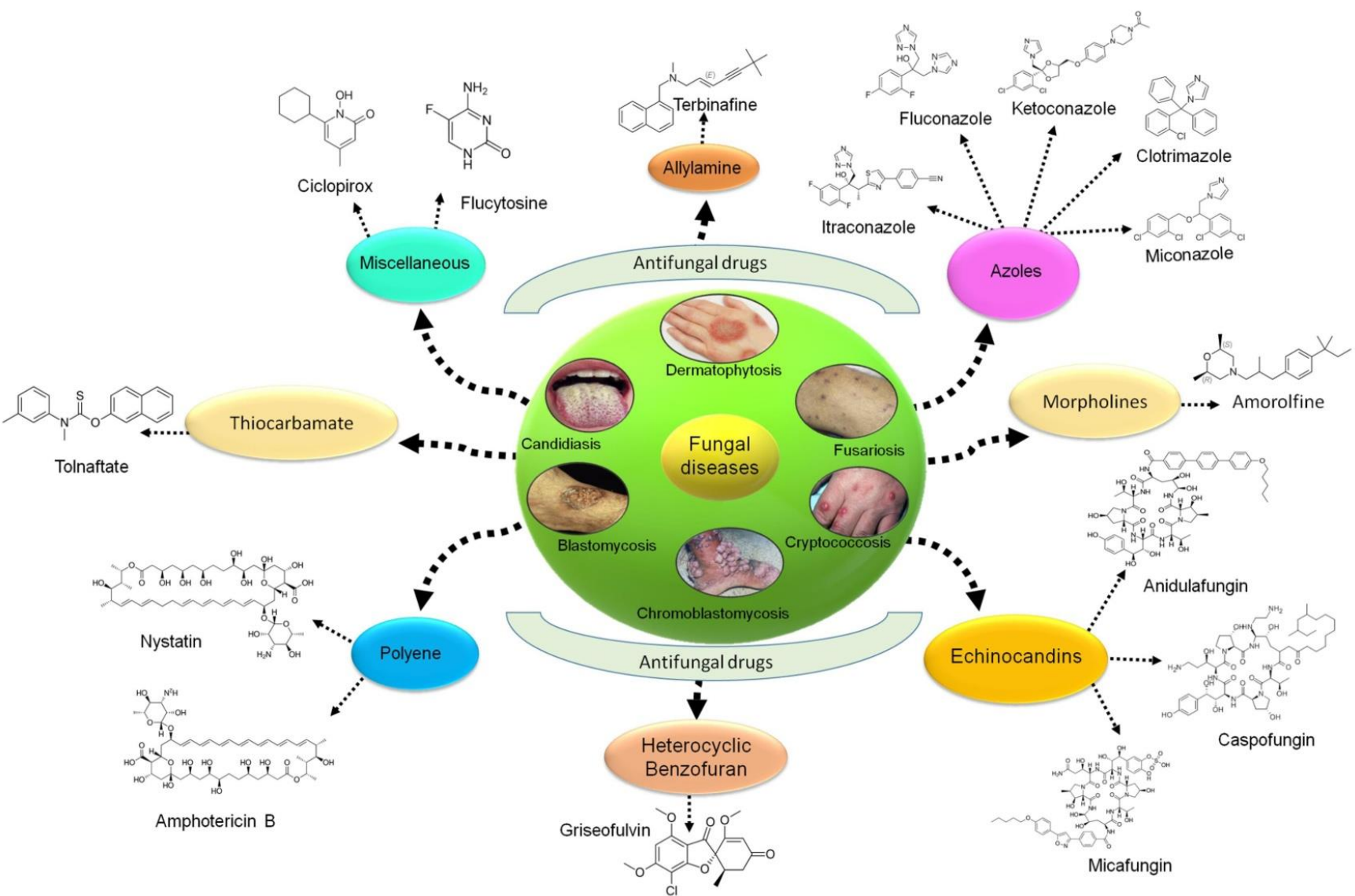

Figure 1. Various types of antifungal drugs currently used in clinics. 


\section{Nanocarriers in Management of Fungal Infections}

Each category of antifungal drug has defined limitations related to a spectrum of activity, development of resistance, and toxicity. Azoles show potential drug-drug interactions in patients. In most cases, the use of AmB becomes ineffective due to the reactivation of fungal infections posttreatment. Further, the excessive and frequent use of azoles leads to the emergence of resistant fungal pathogens. Echinocandins exhibit a narrow antifungal spectrum, but these are better-tolerated. The currently available antifungal therapies are hindered by high toxicity, limited clinical efficacy, and inconsistency in pharmacokinetic properties. Further, drug interactions and adverse drug effects are expected in combination therapy. In this regard, nanotechnology-based approaches exhibit improved inhibitory activity on fungal pathogens at lower concentrations. Nanocarriers also assist in the targeted delivery of antifungal drugs [23].

Nanocarriers possess unique optical, electrical, mechanical, or chemical characteristic features, which show advantages over the conventional dosage form [24]. Nanotechnology is involved in the creation of devices and materials $[24,25]$. A wide variety of nanocarriers used as drug delivery systems (DDS) for the treatment of fungal diseases include phospholipid vesicles (such as liposomes, transfersomes, ethosomes, transethosomes, etc.); non-phospholipid vesicles (spanlastics and niosomes); nanostructured lipid carriers (NLCs); solid lipid nanoparticles (SLNs); nanoemulsions; polymeric nanoparticles (such as chitosan-based nanoparticles); metal oxide nanoparticles; silver nanoparticles (AgNPs); carbon nanotubes (CNTs); and dendrimers (Figure 2).

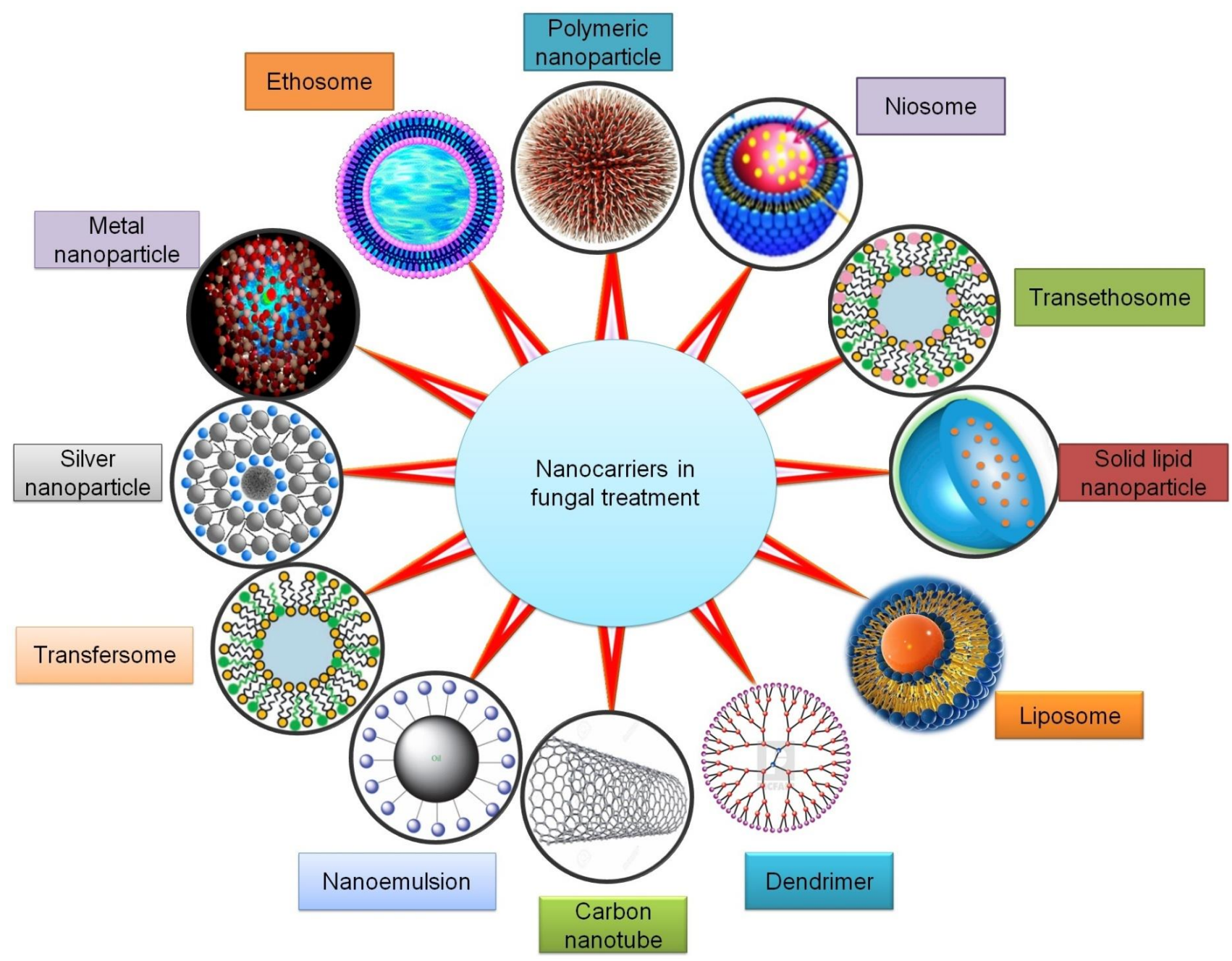

Figure 2. Nanocarriers that can improve therapeutic outcomes in the management of fungal infections. 


\subsection{Vesicle Systems}

\subsubsection{Liposomes}

Liposomes are bilayer vesicles with an aqueous core. This unique arrangement allows the liposomes to perform as an effective DDS for both hydrophobic and hydrophilic drugs [26,27]. Additional attention-grabbing features of liposomes comprise the least toxicity, biocompatibility, high drug load, bioavailability, and sustained release. Cholesterol is employed in liposomes for increasing membrane stiffness, the stabilization of vesicles, and controlling the drug release rate [28].

In this regard, Ambati et al. explored a novel strategy to improve drug efficacy by targeting fungal cells. The AmB-loaded liposomes were synthesized and coated with Dectin-2. Their outcome showed the diminished growth and viability of fungus cells [29]. In a study, Liu and coworkers evaluated the effectiveness of intravitreally administered AmB. C. albicans was inoculated to produce fungal infections inside the vitreous cavities of 46 experimental rabbits. The histopathological data showed that the decreased toxicity of intravitreally administered liposome-bounded antifungal drugs is accompanied by a reduced efficacy. Moreover, in the fungal endophthalmitis treatment, a large dose of liposome-bound AmB (above the required free drug) may be recommended [30].

Veloso et al. fabricated liposomal voriconazole (VCZ) as a safe and effective therapeutic platform for treating fungal infections. The study revealed that the administration of liposomal VCZ resulted in a higher drug accumulation in the kidneys and liver. The protection of VCZ from biological degradation and a reduced metabolic rate resulted in a $30 \%$ AUC (area under the plasma drug concentration-time curve) reduction of an inactive metabolite, VCZ-N-oxide [31].

Giordani et al. designed innovative liposomes to simultaneously deliver two polyphenols, such as gallic acid (GA) and quercetin (Q). The release of developed liposome formulation in the vaginal cavity showed synergistic action to eliminate the infection and diminish the vulvar, vaginal candidiasis symptoms. GA and $Q$ acted in synergy to increase the antioxidant actions of individual polyphenols. The developed polyphenol-loaded liposomes were reported as nontoxic to cells and exhibited stronger anti-inflammatory activity than the free polyphenols and reduced the growth of C. albicans [32].

\subsubsection{Transfersomes}

Biocompatible ultra-deformable/elastic vesicles called Transfersomes are fabricated from natural phospholipids and nonionic surfactants. Transfersomes have gained significant interest in transdermal drug delivery [33]. Since their structures involve hydrophilic and hydrophobic moieties, both drug molecules' categories can be accommodated with extensive solubility. Transfersomes have a higher elasticity rate, resulting in a higher flux rate and penetration across the skin than other vesicular systems [34].

Steinberg developed a topical formulation of a hydrophobic fungicide terbinafine (TF)-loaded in Transfersome ${ }^{\circledR}$ vesicles (TFVs), which have significant in vitro antifungal capacity compared to the plain TF. The study showed that TFVs caused more efficient local damage to the fungal endoplasmic reticulum (ER). Additionally, the outcomes suggested that transfersomes can act independently in the treatment of all types of fungal diseases [35].

Ghannoum et al. designed a transfersome-based liquid spray to deliver the therapeutic drug across the nail bed to treat onychomycosis infections. The Transfersome-designed system demonstrated potent activity against the dermatophyte strains, with minimum inhibitory concentrations (MIC) of $0.03-15 \mathrm{mg} / \mathrm{mL}$ [36]. In a study, Zaky et al. prepared TF-containing transfersomes to compare the antifungal activity and skin permeation rates of different vascular formulations, such as menthosomes, transfersomes, and ethosomes in nonocclusive environments. The ex vivo study of the drug-loaded vesicle displayed a twoto three-fold greater permeation rate compared to the drug suspension. The TF transfer is considered an effective antifungal agent against Aspergillus niger to manage fungal diseases of toenails or fingernails [37]. 


\subsubsection{Ethosomes}

Ethosomes are soft, noninvasive, and malleable drug carriers that allow drugs to spread in the systemic circulation and deep skin layers. Ethosomes, mainly composed of $20-45 \%$ ethanol, $2-5 \%$ phospholipids, and $100 \% w / w$ water, enhance the percutaneous absorption of drugs. A high ethanol concentration makes the ethosomes unique, which confers a negative charge to liposomes and reduces vesicle sizes and the improved bioavailability of therapeutic drugs [38].

Bhalaria et al. formulated FLZ-encapsulated liposomes and ethosomes. Their study examined that the drugs diffused (\%) from ethosomes were almost two-fold greater in contrast to liposomes and three-fold greater than a hydroethanolic solution across rat skin. The results demonstrated that the developed ethosomal DDS yielded improved antifungal activity [39].

Faisal et al. developed an ethosome-based subcutaneous delivery system for VCZ with the ultimate goal to enhance their antifungal properties and drug penetration. The outcome reflected that ethosomes attained a similar inhibition rate against an Aspergillus flavus infection at a two-times lesser drug concentration, contrary to the VCZ solution in dimethylsulfoxide (DMSO). For ethosomes, the obtained drug permeability rate across the abdominal skin was about six times higher than VCZ in hydroalcoholic solution. Likewise, the drug deposited on the skin was found to be greater and reliant on the ethanol concentration [40].

In a study by Akhtar and Pathak, clotrimazole (CLO)-loaded Cavamax W7 composite ethosomes were developed for enhanced drug delivery through the epidermis. The Cavamax W7 composite ethosomal optimized gel displayed a higher $(88.53 \% \pm 2.10 \%)$ drug permeation rate in $8 \mathrm{~h}$. The steady-state flux (Jss) was found to be $3.39 \pm 1.45 \mu \mathrm{g} / \mathrm{cm}^{2} / \mathrm{min}$ in contrast to that of ethosomal gel $\left(1.57 \pm 0.23 \mu \mathrm{g} / \mathrm{cm}^{2} / \mathrm{min}\right)$ [41]

\subsubsection{Transethosomes}

Transethosomes, a combination of both ethosomes and transfersomes, contain phospholipids; a high ethanol concentration (30-40\%); edge activators (span 80 , span 65 , sodium deoxycholate, span 60, tween 20, tween 80, and tween 60); and water. Song et al. architectured a novel carrier based on transethosome for the improved skin penetration of VCZ. Transethosomes containing VCZ were synthesized and compared with ethosomes, conventional liposomes, deformable liposomes, and controlled (polyethylene glycol) solutions. The study data showed that $>90 \%$ of vesicles were recovered among all the vesicles due to the presence of ethanol $(7-30 \%)$. Therefore, transethosomes could serve as a potential subcutaneous DDS for VCZ [42].

The key goal of the research work of Verma and Utreja was to fabricate transethosomes for the effective dermal delivery of econazole nitrate. Transethosomal gel showed more antifungal activity than commercial cream. The transethosomes could deliver econazole nitrate in a controlled manner to eliminate cutaneous candidiasis [43].

\subsubsection{Niosomes}

Niosomes have been discovered as an excellent alternative to liposomes in order to overcome the complications of sterilization, stability, and large-scale production. Niosomes are composed of biodegradable, nontoxic, stable (physically and chemically), and inexpensive nonionic surfactants, which result in targeted and controlled drug release [44].

Goyal and Qureshi prepared ITZ-loaded niosomal gel and demonstrated a prolonged drug release with an increased drug retention and permeation across the skin [45]. Another study focused on the preparation of niosomal gel. An in vitro study showed that $41.18 \% \pm 1.53 \%$ of the drug was released in simulated intestinal fluid within $12 \mathrm{~h}$. The niosomes-based gel formulation displayed prolonged action and improved antifungal activity compared to the non-niosomal formulation [46]. Shirsand et al. designed a successful ketoconazole-loaded niosome employing span 60 and cholesterol (1:0.2) and incorporated it into Carbopol gel (1\%). An in vitro study showed $36.18 \% \pm 1.50 \%$ of the drug release 
within $12 \mathrm{~h}$. The developed formulation reflected a prolonged action with an improved antifungal activity [47]. In a recent study, Abu El-Enin developed FLZ-loaded proniosomal gel by the coacervation phase separation method using different nonionic surfactants. The study showed the potential of proniosomal gel for the topical delivery of an antifungal drug with a slow release for the management of fungal infections [48].

El-Ridy et al. designed nystatin-loaded niosomes using stearylamine (positive) and dicetyl phosphate (negative) as the charge-inducing agents (CIA). The formulation demonstrated a high bioavailability, the least hepatotoxicity, and nephrotoxicity. Therefore, the niosomal system has opened a way for the parenteral administration of antifungal drugs, which results in diminished toxicity and more dynamic antifungal actions [49].

\subsubsection{Spanlastics}

Kakkar and Kaur presented an elastic vesicular drug carrier system (Spanlastics) as a cargo material with good flexibility and ocular permeability in contrast to the nano formulations such as niosomes [50].

Various studies were performed in order to evaluate their flexibility over numerous mucosal membranes. Kaur et al. incorporated the bis-triazole antifungal agent FLZ into an advanced sorbitan (spans)-based spanlastic vesicular system. Spanlastics were found to be three times smaller in size with enhanced drug permeation than niosomal formulations [51]. Additionally, spanlastics can be used over cubosomes (composed of cube-shaped micellar aggregates) without adding an edge activator. Mainly, spanlastics were discovered for their excellent ability to optimize trans-duodenal, trans-ungual, and trans-corneal activity [52-54].

\subsection{Nanoparticles}

\subsubsection{Polymeric Nanoparticles}

Polymeric NPs are biocompatible and biodegradable polymer-based delivery systems within the range of 10-1000 $\mathrm{nm}$ in which drugs can easily dissolve, encapsulate, or conjugate. Chitosan, a nontoxic, abundant, biodegradable polymer, is a linear amino polysaccharide. Ing et al. determined the antifungal activity of chitosan-based NPs against Fusarium solani, A. niger, and C. albicans. The chitosan NPs with zeta potential from +22 to $+55 \mathrm{mV}$ exhibited enhanced inhibitory activity against $F$. solani (MIC of low molecular weight (LMW) NPs $=0.86-1.2 \mathrm{mg} / \mathrm{mL}$ and MIC of high molecular weight (HMW) NPs $=0.5-1.2 \mathrm{mg} / \mathrm{mL}$ ) and C. albicans (MIC of LMWNPs $=0.25-0.86 \mathrm{mg} / \mathrm{mL}$ and MIC of HMWNPs $=0.6-1.0 \mathrm{mg} / \mathrm{mL}$ ) as compared with the solution (MIC $=3 \mathrm{mg} / \mathrm{mL}$ for F. solani and C. albicans, as well as LMWNPs and HMWNPs). The inhibitory action was found to be based on the zeta potential and particle size of chitosan NPs [55]. The chitosan NPs exhibited good antifungal activity compared to AmB and reduced the cytotoxicity in L929 fibroblast cells [56]. Ling et al. synthesized a novel nanoplatform containing ITZ (ITZ-NP) for an effective fungal treatment with sustained drug delivery. A slight venous irritation and very mild hemolysis represented much-improved biocompatibility compared to the marketed formulations [57].

\subsubsection{Metal Nanoparticles}

Arciniegas-Grijalba et al. fabricated zinc oxide ( $\mathrm{ZnO})$-loaded NPs and found that a concentration of $9 \mathrm{mmol} / \mathrm{L}$ for the sample restricted the E. salmonicolor growth, reflecting more significant antifungal activity [58]. Sawai and Yoshikawa evaluated the antifungal activities of calcium oxide $(\mathrm{CaO})$, magnesium oxide $(\mathrm{MgO})$, and $\mathrm{ZnO}$ powders against C. albicans, Rhizopus stolonifer, A. niger, and Saccharomyces cerevisiae. The results showed that the $\mathrm{CaO}$ and $\mathrm{MgO}$ powders unveiled the antimicrobial properties against all fungi presented in the study [59].

Gutierrez and coworkers reported the advantages of reverse micelles to fabricate $<5$-nm silver, gold, and gold-silver NPs with antifungal activity against five Candida strains accountable for several infections/diseases. Developed highly reactive and monodis- 
persed NPs with $<5$-nm sizes showed great antifungal action against $C$. krusei, $C$. parapsilosis, C. glabrata, C. albicans, and C. guillermondii with $\mathrm{MIC}_{50}<0.7 \mathrm{ppm}$. Thus, NPs are considered promising nanoplatforms to form alternative therapies to treat fungal diseases/infections [60].

Pereira et al. characterized and explored the potential of AgNPs against A. oryzae and Penicillium chrysogenum. The antifungal drug terbinafine revealed lower MIC values $(0.0063-0.0251 \mathrm{~g} / \mathrm{mL})$ for the experimental strains. Chemically fabricated AgNPs showed antifungal action against all T. rubrum strains, whereas biologically fabricated AgNPs showed more activity than FLZ but less than ITZ, terbinafine, and chemically synthesized AgNPs. Hence, the outcomes showed that biologically developed AgNPs might be utilized as antifungal agents to treat dermatophytes [61]. Recently, Bocate et al. determined the antifungal potential of biogenic AgNPs produced by simvastatin and fungi (alone or in combination) against three toxic species relating to the genera Aspergillus section Flavi (A. nomius, A. parasiticus, and A. flavus) and Circumdati section (A. melleus and A. ochraceus). These results showed significant advantages of combined AgNPs and simvastatin regarding the inhibition of fungal growth [62].

Nasrollahi et al. revealed the antifungal property of AgNPs on C. albicans and S. cerevisiae. The study indicated that AgNPs have extensive antifungal activity compared to other antifungal agents, worth further research for clinical use [63].

Mallmann et al. introduced AgNPs in which ribose and sodium dodecyl sulfate were used as the reducing agent and stabilizer, respectively. While the outcome showed that stable NPs with $12.5 \pm 4.9$-nm sizes exhibited more antifungal action against Candida spp. [64]. Alananbeh et al. researched the effective dose and shape of AgNPs needed to treat fungi present in the wastewater. The authors found that rod-shaped NPs resulted in the least fungi growth compared with cube-shaped NPs [65]. AgNPs are promising nanocarriers for drug delivery [66].

\subsubsection{Silver Bromide/Cationic Polymer Nanocomposite}

Zhang et al. engineered poly-methyl methacrylate (PMMA) dental resins for longlasting and strong antifungal properties against $C$. albicans necessary for denture stomatitis prevention. The toxicity to human dental pulp cells (HDPCs), the mechanical applications, and the fungal growth inhibition capacity of cationic polymer nanocomposite/silver bromide (NPVP/AgBr)-functionalized PMMA dental resins were demonstrated. Moreover, the antifungal property increased with the increased NPVP/AgBr incorporated antimicrobial composite. The HDPCs growth rate was found to be greater than 75\% [67].

\subsubsection{Solid Lipid Nanoparticles and Nanostructured Lipid Carriers}

Solid lipid nanoparticles (SLNs) are emerging as alternative nanocarriers to the colloidal systems for targeted and controlled delivery [68]. The SLNs can be prepared by utilizing lipids, which have less-arranged crystal lattice structures like glyceryl-behenate and glyceryl-monostearate. These lipids favor effective drug inclusion compared to those synthesized using extremely ordered crystal lattices structures such as cetyl-palmitate, beeswax, solid paraffin, and tripalmitate. The SLNs have advantages, like good acceptability, less risk of acute and chronic toxicity, improved bioavailability, precise targeting, controlled release, encapsulation, and the prevention of unstable compounds from degradation and easy, large-scale production techniques [69].

Nanostructured lipid carriers (NLCs) consist of a higher concentration of liquid lipids than any other architecture. The solubility of therapeutic drugs in liquid lipids is more as compared to solid lipids. Consequently, NLCs show a sustained release and increased drug loading, thus evading loss and leading to solid lipid decomposition. The NLCs are established as an advancement over the SLNs. The NLCs are fabricated by monitoring the mixture of SLNs with liquid oil, foremost to singular nanostructures in the matrix form. The possible disadvantage of SLNs is the predetermined drug-loading capacity and drug 
leaching during storage. In contrast, NLCs represent the improved EE of drugs due to extra space for drug loading by liquid lipids [70].

El-Housiny et al. researched and fabricated FLZ-loaded SLN-based topical gels with the ultimate goal of improvement in the drug efficiency for Pityriasis versicolor treatment. The drug showed a sustained drug release with a 1.4-fold improved therapeutic response [71]. In another study, Jansook et al. investigated the effect of drug EE, drug release, and the biopharmaceutical properties of AmB-based lipid formulations. Their observations concluded that AmB-loaded SLNs showed an enhanced solubility of AmB by combining lecithin and resulted in an extended-release with diminished toxicity and improved antifungal activity [72].

Gratieri et al. compared the physio-pathological conditions of nails and skin to highlight the unrevealed applications of lipid NPs in onychomycosis. The fabrication techniques and ingredients of NPs influence the EE, in vitro fungal activity, drug release, and stability. Lipid NPs like NLC and SLN showed great potential in skin permeation. The VCZ-loaded NLC significantly influenced the depth penetration of an encapsulated cargo drug and allowed deep penetration in porcine hooves compared to the unloaded drug. The NLC and SLN helped in reaching a high EE and cutaneous delivery [73]. Moreover, Souto and Müller designed NLC and SLN-based semi-solid preparation using Carbopol ${ }^{\circledR} 934$. After a shelf-life of 2 years, the results showed $>95 \%$ of CLO and $<30 \%$ of ketoconazole present in the developed formulations [74].

\subsection{Nanoemulsions}

Nanoemulsions (NEs) are the transporters of drug particles with colloidal molecular arrangements in submicron sizes $(10-1000 \mathrm{~nm})$ [75]. Yang et al. developed sulconazoleloaded nanoemulsions (SCZ-NEs) for the improvement of antifungal activity and transdermal permeation. The optimized formulation exhibited a greater permeability (1.7-fold) and inhibition rate $(20.4 \pm 2.5 \mathrm{~mm}$ and $23.5 \pm 2.4 \mathrm{~mm})$ against T. rubrum and C. albicans, respectively. Therefore, SCZ-NEs effectively solved the poor solubility issues, promoted skin permeation, and improved the antifungal activity of SCZ. So, the percutaneous administration of SCZ-NEs can be helpful for the treatment of fungal infections of the skin induced by T. rubrum and C. albicans [76].

Garcia et al. demonstrated the potential of the NB-201 nanoemulsions against humanpathogenic fungi. It was observed that NB-201 significantly decreased the fungal growth at the site of infection and displayed an improved curing property in terms of inhibition activity against the development of other fungal pathogens, like A. fumigatus, Cryptococcus spp., and Mucorales. Due to their nature, there are the least chances of developing drug resistance, which results in a novel treatment for skin infections or fungal wounds [77].

\subsection{Carbon Nanotubes}

$\mathrm{Wu}$ and coworkers prepared antifungal $\mathrm{AmB}$ formulations by grouping single-walled CNTs (SWCNTs) and multi-walled CNTs (MWCNTs) with fluorescein. These were represented as more effective for human Jurkat lymphoma T cells [78]. The AmB-attached CNTs showed less mammalian toxicity when compared to free AmB, as well as good activity against many fungal strains and multidrug-resistant fungal cells. The free AmB-based mammalian toxicity can be reduced by forming conjugations with CNT [79]. As the exterior wall of pristine CNTs is inert, there is a need to alter the CNT surface by non-covalent and covalent changes for better biocompatibility and solubility [80]. In the former method, the long-chain polymers and, in the latter method, direct covalent changes are incorporated for altering CNT surfaces. Most of the current chemical approaches aim to form a strong bond between CNTs and coupling agents. Sometimes, the functionalization of CNTs causes a loss of mechanical strength and more time for purification [81]. The CNTs are both exceptional DDS and novel engineered vehicles for carrying altered genes and single-stranded RNAs [82-85]. 
Benincasa et al. prepared two conjugates amid functionalized CNTs ( $f$-CNTs) and AmB. The calculated MIC values for $f$-CNT-AmB conjugates were more as compared to $\mathrm{AmB}$ and $\mathrm{AmB}$ with sodium deoxycholate (AmBD), which suggested a nonlytic mechanism of action (MOA) and did not present any significant adverse effect on the Jurkat cell line at antifungal concentrations [79]. The molecular mechanisms for multi-walled carbon nanotube (MWCNT)-induced in vivo toxicity on innate immunity are still largely unclear. Considering the potential of Caenorhabditis elegans for the study of the innate immune response of animals, we employed this in vivo assay system to investigate the effects of MWCNTs on the innate immune response of animals and the underlying mechanisms. A pre-exposure to MWCNTs at concentrations more than $100 \mu \mathrm{g} / \mathrm{L}$ enhanced the adverse effect of fungal infections in reducing the lifespan. With regard to the underlying cellular mechanisms, we found that MWCNT pre-exposure enhanced the colony formation of Candida albicans in the body of nematodes and suppressed the innate immune response of nematodes by decreasing the expression levels of some antimicrobial genes. With regard to the underlying molecular mechanisms, we found that MWCNTs decreased the expression levels of the pmk-1, sek-1, and nsy-1 genes encoding the p38 mitogen-activated protein kinase (MAPK) signaling pathway and inhibited the translational expression of PMK$1::$ GFP in the intestines and the phosphorylation of PMK-1. Epistasis assays showed that MWCNTs required the involvement of the p38 MAPK signaling pathway mediated by an NSY-1-SEK-1-PMK-1 cascade to enhance the toxicity of the fungal infection, increase the fungal colony formation, and suppress the innate immune response. Thus, our results suggest that MWCNTs may possess immunoinhibitory effects by affecting the functions of the p38 MAPK signaling pathway. Our study also provides meaningful insights into the role of the innate immune system of hosts against the toxicity of environmental toxicants. Shakoor et al. fabricated MWCNTs and investigated their impact on the essential immune system of animals and related fundamental mechanisms. Regarding cellular mechanisms, MWCNTs enhanced the colony development of $C$. albicans in the nematodes body and reduced the significant immune action of nematodes via reducing the expression stages of various antimicrobial genes. The MWCNTs decreased the expression levels of the sek-1, pmk-1, and nsy-1 genes encrypting the signaling pathway of p38 mitogen-activated protein kinase (MAPK). Thus, the results suggested that MWCNTs could hold immunoinhibitory activity by influencing the roles of the p38 MAPK signaling path and provided evocative immune system action against the environmental toxicants [86].

Vikelouda et al. assessed the antifungal property of AmBD-conjugated $f$-CNTs against C. parapsilosis and C. albicans full-grown biofilms. The data revealed that AmBD-conjugated $f$-CNTs contained $85.65 \% \mathrm{AmBD}$ and $-23.8 \mathrm{mV}$ zeta potential, presenting a stable performance of the nanoconjugates. The $\mathrm{MIC}_{50}$ of $\mathrm{AmBD}$ against $C$. parapsilosis and C. albicans isolate was found to be $0.25 \mathrm{mg} / \mathrm{L}$ and $1 \mathrm{mg} / \mathrm{L}$, respectively. The results exhibited that the $f$-CNTs AmBD and AmBD showed comparable antibiofilm properties for both fungal biofilms and concluded that $C$. parapsilosis showed more resistance than $C$. albicans (at concentrations $\geq 1 \mathrm{mg} / \mathrm{L})$ [87].

Wang et al. showed an improved inhibition rate in spore germination and elongation using MWCNT-derived nanomaterials compared with pristine MWCNTs for the plant pathogenic fungi F. graminearum. Thus, after treatment with a concentration of $500 \mu \mathrm{g} / \mathrm{mL}$ of MWCNTs containing various surface groups (COOH-, $\mathrm{NH}_{2-}^{-}$, and $\left.\mathrm{OH}-\right)$, the spore length reduced from $54.5 \mu \mathrm{m}$ to $28.3 \mu \mathrm{m}, 29.5 \mu \mathrm{m}$, and $27.4 \mu \mathrm{m}$, respectively. Further, the germination of the spore was interestedly inhibited to about $18.2 \%$ of the germination rate by $f$-MWCNTs, which was three-fold lesser than that of the pristine MWCNTs [88].

Pienko et al. proposed the hydroxylated and pristine architectures of the $C_{240}$ fullerene and SWCNTs as nanotransporters of the existing imidazoles (e.g., econazole, tioconazole, and sulconazole) to enhance their pharmacokinetic characteristics, such as absorption, distribution, metabolism, and excretion. It was observed that the adsorption energies of the azoles were dependent on surface modifications and the type of nanotransporter. The CNT and fullerene surface hydroxylation gave a chance for the chemisorption of the 
experimented antifungal agents. The complexes of hydroxylated and pristine nanotubes displayed thermodynamic stability, while the fullerenes complexes were found to be thermodynamically unstable. Their kinetic stability was noteworthy, which allowed for the formation of such structures. The instability of energy could improve the liberation of the loaded molecule, which is advantageous for the release of the drug [89].

\subsection{Dendrimers}

Dendrimers with a low polydispersity index (PDI) and precise surface characters involve three main structural parts: central, branches, and active surface groups [90,91]. Different families of dendrimers like PAMAM, poly(propylene imine) (PPI), carbosilanes, poly-l-lysines, and phosphorous dendrimers have been extensively explored for their usage in biomedical sciences [92,93].

Dendrimers with core-shell nanostructures, along with defined designs and less PDI, are manufactured in a layer-by-layer fashion around a central unit, resulting in the regulation of oversizing, surface functionality, and branching points [94]. The PAMAM dendrimers are the most focused nanoplatform, with a well-established structure, shape, low PDI (nearly 1), compatibility, and good solubility. Additionally, their globular construction offers a solid assembly $(1-10 \mathrm{~nm})$ for movement via biological layers as a novel carrier for the increased solubility of water-insoluble drugs. Besides, PAMAM dendrimers are elegant additives in different drug administration modes, like IV, oral transdermal, and ocular delivery [95].

The surface engineering of dendrimers affects cell absorption. Adsorption endocytosis occurs within the cells by binding with negatively charged proteoglycans present inside the cell membrane with cationic dendrimers. Clotrimazole (CLO), an interesting antifungal agent belonging to the azole type, is widely used as first-line therapy for Candidiasis, along with econazole and miconazole. Winnicka and coworkers successfully enhanced the solubility of the antifungal drug CLO by encapsulating it in dendrimers and observed its enhanced solubility in the PAMAM- $\mathrm{NH}_{2}$ dendrimer in contrast to PAMAM-OH dendrimers [96]. In an experiment by Gupta et al., the enhanced solubility of $\mathrm{AmB}$ was obtained by forming complexes with PPI dendrimers [97].

It is very interesting to mention that dendrimer-based formulations like dendrimeric lipopeptides and Trp-rich dendrimeric peptides alone showed some antifungal activity $[98,99]$. Winnicka et al. showed that the charges present on the surface of PAMAM dendrimers sturdily affected the enhancement of antifungal activity and solubility of antifungal drugs [100]. Khairnar et al. examined the potential of different generations of PAMAM and PPI dendrimers to improve the antifungal activity of Terbinafine and Nystatin. The data presented that both the dendrimers enhanced the antifungal properties against $A$. niger, S. cerevasae, and C. albicans [101].

\section{Toxicological Overview}

While the number of NPs types and applications continues to increase, studies to characterize their effects after exposure and to address their potential toxicity are few in comparison. Compared to conventional substances in a microscale, NPs (diameter $<100 \mathrm{~nm}$ ) stand on a huge reactive surface able to interact with biological systems and cause toxic effects. Most of the antifungal drugs have poor water solubility, which tends to show a lower absorption and bioavailability. It can be improved by forming complexes using nanocarriers. By virtue of their nano sizes, they have greater interactions with biological surfaces, with pro and con effects [102]. Schematic mechanisms of cytotoxic activity of antifungal drug-loaded nanocarriers are represented in Figure 3. 


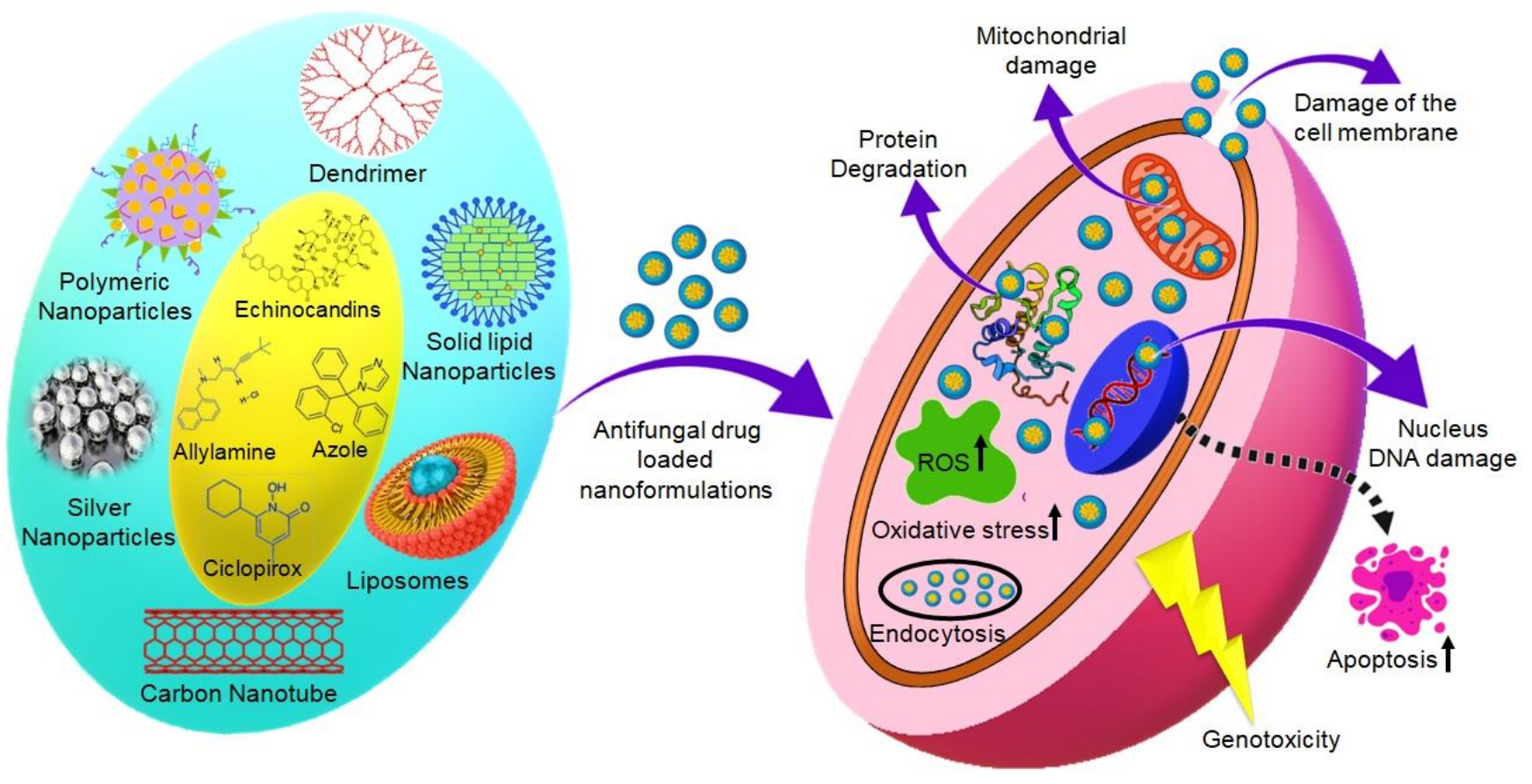

Figure 3. Schematic mechanisms of cytotoxic activity of antifungal drug-loaded nanocarriers.

The cytotoxicity of chitosan NPs (ChNPs) in terms of the percentage of viable cells and percentage of cytotoxicity after their respective treatments has been analyzed. At a dose of $300 \mathrm{mg} / \mathrm{mL}$, ChNPs killed $74.16 \%$ of the cell after $24-\mathrm{h}$ incubation. The $\mathrm{LD}_{50}$ value was obtained as $64.21 \mathrm{mg} / \mathrm{mL}$. The inhibition rate profile of ChNPs indicated that the inhibition of cell viability was found to be dose-dependent [56].

Spanlastics are nanosized and elastic. Both developed formulations, and the corresponding empty vesicles have not shown any significant toxic effect on the cell proliferation of HGF compared to the control $(p<0.05)$ at $1 \%$ and $5 \% \mathrm{KTZ}$ in the cell culture suspension medium. There was higher cell viability in the case of blank and drug-loaded vesicles than free drug suspension. Hence, it may be concluded that vesicles do not contribute to cell cytotoxicity [50].

Different generations of the PAMAM dendrimer are used to enhance the solubility of $\mathrm{AmB}$, whose clinical use is restricted due to poor solubility and nephrotoxicity $[103,104]$. For topical DDS, dendrimers might be advantageous for quick results of topical irritation. Currently, there are no such studies that can clarify the cationic toxicity of topical dendrimers. The lower groups of cationic dendrimers have exhibited better penetration than the advanced ones [105-107].

In a recent study, AgNPs were synthesized using different polymer/protein mixtures, such as k-carrageen-hydrolyzed collagen (AgNPcolCarr), cashew gum-hydrolyzed collagen (AgNPcolCashew), and agar-hydrolyzed collagen (AgNPcolAgar) and showed 2.0- and 6.5-fold less cytotoxicity than AgNPcol, respectively. AgNPcolCarr demonstrated a MIC value of 62.5 and $31.25 \mu \mathrm{m} / \mathrm{mL}$ against $E$. coli and P. aeruginosa, respectively. The MOA of AgNPs against yeasts may be related to the generation of free radicals that lead to apoptosis [108].

In a study, Perez et al. tested the toxicity of empty ultra-deformable liposomes (UDL). The formulations F3 and F4 did not reduce the mitochondrial activity of Keratinocyte (HaCaT) and J774 cells; nonetheless, F4 produced 30\% lactate dehydrogenase (LDH) leakage in HaCaT cells at $2.9 \mathrm{mg} / \mathrm{mL}$ SPC. The membrane damage was more pronounced on phagocytic (J774) than on nonphagocytic cells (HaCaT) [109]. 


\section{Conclusions}

Fungal infections may lead to chronic diseases and death. The current antifungal drugs used to treat topical infections show associated toxicity and decreased therapeutic outcomes in unsuitable physicochemical performances. Although antifungal drugs are designed to treat invasive fungal infections (IFIs), high mortality and morbidity, costly treatment, and long stay in the hospital are associated with IFIs. The currently available antifungal drugs show some limitations, including drug-drug interactions, spectrum activity, pharmacodynamic and pharmacokinetic profiles, toxicity, and variability in absorption. In this context, combination therapy can be a potential strategy for improving the efficacy of two or more drugs against drug-resistant fungal isolates. The development of new antifungal therapy will improve the quality of patient life by reducing the therapy time.

The utilization of antifungal agents in the treatment of fungal infections can prompt the commencement of antifungal resistance. Regardless of the progress made so far in antifungal treatments, the conjecture of resistance is still of significant concern in clinical practice. The further advancement in the systemic treatment had a premise in amphotericin B lipid preparations, which have increasingly good symptoms. Following the lipid preparations of azoles, the other class of antifungal specialists that was exceptionally compelling in treating some of the systemic mycoses was the echinocandins class. The echinocandins displayed less renal toxicity than amphotericin B; however, they still have noteworthy hepatotoxicity and were more costly than the azoles. Antifungal resistance is now emerging as one of the clinically significant issues in patients requiring long-term prophylactics or who have a background marked by antifungal use. Additionally, resistance advancement is affecting the study of the disease transmission of Candida contamination, evidenced by a change from the albicans to the non-albicans Candida.

Despite an increasing number of reports about the advancement in antifungal therapy, the number of cases of fungal infection is still high. New strategies for antifungal therapy, rational drug design, and target identification can considerably boost the development of new antifungal drugs for better cures and quality of life for patients. New antifungal agents like isavuconazole are becoming better options in fungal treatments.

\section{Future Perspective}

Fungal infections kill more than one million humans each year. Thus, at least one in five people are suffering from fungal infections. Neonates and geriatrics are at a higher risk of death due to fungal infections.

To increase the efficiency of the currently available antifungals, efforts are required to enhance the bioavailability, reduce the toxicity, combat the resistance, and improve the antifungal spectrum. In this regard, to overcome these limitations, nanotechnology-based drug delivery systems (nanocarriers) have attracted the attention of researchers owing to their remarkable features, functionalization possibilities, and biocompatible performances. Nanocarriers such as liposomes, transferosomes, ethosomes, transethosomes, niosomes, spanlastics, nanoparticles, nanoemulsions, carbon nanotubes, and dendrimers, among other promising nanotechnological approaches, can improve the therapeutic outcomes for drugs used to treat fungal infections.

Nanotechnology-based formulations have exhibited promising results to improve the aqueous solubility, efficiency, and stability of antifungal drugs and the target of infected tissues. Despite these features of NPs, only a few NP-based antifungal drug formulations are available in the market. Therefore, further research is required to overcome the issues associated with drug loading, stability, standardization, the economic aspects, and the challenges to boost the safe translation of the developed antifungal nanotechnology from the lab to the clinic. 
Author Contributions: Conceptualization, V.M., M.S., and P.N.; writing-original draft preparation, V.M., M.S., Y.M., P.N., A.A.A.A., Á.S.-A., and M.M.T.; writing-review and editing, V.M., M.S., Y.M., N.C., P.N., K.S., A.A.A.A., S.H.S., H.B., Á.S.-A., and M.M.T.; and supervision, V.M. and M.M.T. All authors have read and agreed to the published version of the manuscript.

Funding: This research received no external funding.

Institutional Review Board Statement: Not applicable.

Informed Consent Statement: Not applicable.

Data Availability Statement: Not applicable.

Conflicts of Interest: The authors declare no conflict of interest.

\section{References}

1. Nami, S.; Mohammadi, R.; Vakili, M.; Khezripour, K.; Mirzaei, H.; Morovati, H. Fungal vaccines, mechanism of actions and immunology: A comprehensive review. Biomed. Pharmacother. 2019, 109, 333-344. [CrossRef] [PubMed]

2. Janbon, G.; Quintin, J.; Lanternier, F.; d'Enfert, C. Studying fungal pathogens of humans and fungal infections: Fungal diversity and diversity of approaches. Microbes Infect. 2019, 21, 237-245. [CrossRef] [PubMed]

3. Sharma, B.; Nonzom, S. Superficial mycoses, a matter of concern: Global and Indian scenario-an updated analysis. Mycoses 2021. [CrossRef]

4. Souza, A.C.O.; Amaral, A.C. Antifungal therapy for systemic mycosis and the nanobiotechnology era: Improving efficacy, biodistribution and toxicity. Front. Microbiol. 2017, 8, 336. [CrossRef] [PubMed]

5. Verma, S.; Utreja, P. Vesicular nanocarrier based treatment of skin fungal infections: Potential and emerging trends in nanoscale pharmacotherapy. Asian J. Pharm. Sci. 2019, 14, 117-129. [CrossRef]

6. Vallabhaneni, S.; Mody, R.K.; Walker, T.; Chiller, T. The global burden of fungal diseases. Infect. Dis. Clin. N. Am. 2016, 30, 1-11. [CrossRef] [PubMed]

7. Brown, G.D.; Denning, D.W.; Gow, N.A.R.; Levitz, S.M.; Netea, M.G.; White, T.C. Hidden killers: Human fungal infections. Sci. Transl. Med. 2012, 4, 165rv13. [CrossRef]

8. Grover, S.; Roy, P. Clinico-mycological profile of superficial mycosis in a hospital in North-East India. Med. J. Armed Forces India 2003, 59, 114-116. [CrossRef]

9. Brown, A.J.P.; Gow, N.A.R.; Warris, A.; Brown, G.D. Memory in fungal pathogens promotes immune evasion, colonisation, and infection. Trends Microbiol. 2019, 27, 219-230. [CrossRef]

10. Hay, R. Therapy of skin, hair and nail fungal infections. J. Fungi 2018, 4, 99. [CrossRef] [PubMed]

11. Verekar, S.A.; Deshmukh, S.K. Keratinophilic fungi distribution, pathogenicity and biotechnological potentials. In Developments in Fungal Biology and Applied Mycology; Springer: Singapore, 2017; Volume 75-97.

12. Rai, M.; Ingle, A.P.; Pandit, R.; Paralikar, P.; Gupta, I.; Anasane, N.; Dolenc-Voljč, M. Nanotechnology for the treatment of fungal infections on human skin. In The Microbiology of Skin, Soft Tissue, Bone and Joint Infections; Academic Press: Cambridge, MA, USA, 2017; pp. 169-184.

13. Berger, A.P.; Ford, B.A.; Brown-Joel, Z.; Shields, B.E.; Rosenbach, M.; Wanat, K.A. Angioinvasive fungal infections impacting the skin: Diagnosis, management, and complications. J. Am. Acad. Dermatol. 2019, 80, 883-898. [CrossRef] [PubMed]

14. Noé, W.; Murhekar, S.; White, A.; Davis, C.; Cock, I.E. Inhibition of the growth of human dermatophytic pathogens by selected australian and asian plants traditionally used to treat fungal infections. J. Mycol. Med. 2019, 29, 331-344. [CrossRef]

15. Shields, B.E.; Rosenbach, M.; Brown-Joel, Z.; Berger, A.P.; Ford, B.A.; Wanat, K.A. Angioinvasive fungal infections impacting the skin: Background, epidemiology, and clinical presentation. J. Am. Acad. Dermatol. 2019, 80, 869-880. [CrossRef] [PubMed]

16. Cohen, L.; Seminario-Vidal, L.; Lockey, R.F. Dermatologic problems commonly seen by the allergist/immunologist. J. Allergy Clin. Immunol. Pract. 2020, 8, 102-112. [CrossRef]

17. Khurana, A.; Sardana, K.; Chowdhary, A. Antifungal resistance in dermatophytes: Recent trends and therapeutic implications. Fungal Genet. Biol. 2019, 132, 103255. [CrossRef]

18. Chang, Y.L.; Yu, S.J.; Heitman, J.; Wellington, M.; Chen, Y.L. New facets of antifungal therapy. Virulence 2017, 8, 222-236. [CrossRef] [PubMed]

19. Nivoix, Y.; Ledoux, M.-P.; Herbrecht, R. Antifungal therapy: New and evolving therapies. Semin. Respir. Crit. Care Med. 2020, 41, 158-174. [CrossRef] [PubMed]

20. Carmona, E.M.; Limper, A.H. Overview of treatment approaches for fungal infections. Clin. Chest Med. 2017, 38, 393-402. [CrossRef]

21. Weinstein, A.; Berman, B. Topical treatment of common superficial tinea infections. Am. Fam. Physician 2002, 65, $2095-2102$.

22. Nigam, P.K. Antifungal drugs and resistance: Current concepts. Our Dermatol. Online 2015, 6, 212-221. [CrossRef]

23. Alghuthaymi, M.A.; Hassan, A.A.; Kalia, A.; Sayed El Ahl, R.M.H.; El Hamaky, A.A.M.; Oleksak, P.; Kuca, K.; Abd-Elsalam, K.A. Antifungal nano-therapy in veterinary medicine: Current status and future prospects. J. Fungi 2021, 7, 494. [CrossRef] 
24. Patil, A.; Mishra, V.; Thakur, S.; Riyaz, B.; Kaur, A. Nanotechnology derived nanotools in biomedical perspectives: An update. Curr. Nanosci. 2019, 15, 137-146. [CrossRef]

25. Baysal, A.; Saygin, H.; Ustabasi, G.S. Physicochemical transformation of $\mathrm{ZnO}$ and $\mathrm{TiO}_{2}$ nanoparticles in sea water and its impact on bacterial toxicity. Environ. Health Eng. Manag. 2019, 6, 73-80. [CrossRef]

26. Zhang, Y.; Huang, L. Liposomal delivery system. In Nanoparticles for Biomedical Applications; Elsevier: Amsterdam, The Netherlands, 2020; pp. 145-152.

27. Eloy, J.O.; Claro de Souza, M.; Petrilli, R.; Barcellos, J.P.A.; Lee, R.J.; Marchetti, J.M. Liposomes as carriers of hydrophilic small molecule drugs: Strategies to enhance encapsulation and delivery. Colloids Surf. B Biointerfaces 2014, 123, 345-363. [CrossRef] [PubMed]

28. Bozzuto, G.; Molinari, A. Liposomes as nanomedical devices. Int. J. Nanomed. 2015, 10, 975-999. [CrossRef]

29. Ambati, S.; Ellis, E.C.; Lin, J.; Lin, X.; Lewis, Z.A.; Meagher, R.B. Dectin-2-targeted antifungal liposomes exhibit enhanced efficacy. mSphere 2019, 4. [CrossRef]

30. Liu, K.R.; Peyman, G.A.; Khoobehi, B. Efficacy of liposome-bound amphotericin B for the treatment of experimental fungal endophthalmitis in rabbits. Investig. Ophthalmol. Vis. Sci. 1989, 30, 1527-1534.

31. Veloso, D.F.M.C.; Benedetti, N.I.G.M.; Ávila, R.I.; Bastos, T.S.A.; Silva, T.C.; Silva, M.R.R.; Batista, A.C.; Valadares, M.C.; Lima, E.M. Intravenous delivery of a liposomal formulation of voriconazole improves drug pharmacokinetics, tissue distribution, and enhances antifungal activity. Drug Deliv. 2018, 25, 1585-1594. [CrossRef]

32. Giordani, B.; Basnet, P.; Mishchenko, E.; Luppi, B.; Škalko-Basnet, N. Utilizing liposomal quercetin and gallic acid in localized treatment of vaginal candida infections. Pharmaceutics 2019, 12, 9. [CrossRef]

33. Ravi, K.; Singh, M. Rajini, B.; Nimratha, S.; Rana, A.C. Transferosomes: A novel approach for transdermal drug delivery. Int. Res. J. Pharm. 2012, 3, 20-24.

34. Wu, P.-S.; Li, Y.-S.; Kuo, Y.-C.; Tsai, S.-J.J.; Lin, C.-C. Preparation and evaluation of novel transfersomes combined with the natural antioxidant Resveratrol. Molecules 2019, 24, 600. [CrossRef]

35. Steinberg, G. Cytoplasmic fungal lipases release fungicides from ultra-deformable vesicular drug carriers. PLoS ONE 2012, 7, e38181. [CrossRef]

36. Ghannoum, M.; Isham, N.; Herbert, J.; Henry, W.; Yurdakul, S. Activity of TDT 067 (terbinafine in Transfersome) against agents of onychomycosis, as determined by minimum inhibitory and fungicidal concentrations. J. Clin. Microbiol. 2011, 49, 1716-1720. [CrossRef] [PubMed]

37. Zaky, A. Comparative study of terbinafine hydrochloride transfersome, methosome and ethosome nanovesicle formulations via skin permeation and antifungal efficacy. Al-Azhar J. Pharm. Sci. 2016, 54, 18-36.

38. Romero, E.L.; Morilla, M.J. Highly deformable and highly fluid vesicles as potential drug delivery systems: Theoretical and practical considerations. Int. J. Nanomed. 2013, 8, 3171-3186. [CrossRef] [PubMed]

39. Bhalaria, M.K.; Naik, S.; Misra, A.N. Ethosomes: A novel delivery system for antifungal drugs in the treatment of topical fungal diseases. Indian J. Exp. Biol. 2009, 47, 368-375. [PubMed]

40. Faisal, W.; Soliman, G.M.; Hamdan, A.M. Enhanced skin deposition and delivery of voriconazole using ethosomal preparations. J. Liposome Res. 2018, 28, 14-21. [CrossRef]

41. Akhtar, N.; Pathak, K. Cavamax W7 composite ethosomal gel of clotrimazole for improved topical delivery: Development and comparison with ethosomal gel. AAPS PharmSciTech 2012, 13, 344-355. [CrossRef]

42. Song, C.K.; Balakrishnan, P.; Shim, C.-K.; Chung, S.-J.; Chong, S.; Kim, D.-D. A novel vesicular carrier, transethosome, for enhanced skin delivery of voriconazole: Characterization and in vitro/in vivo evaluation. Colloids Surf. B Biointerfaces 2012, 92, 299-304. [CrossRef]

43. Verma, S.; Utreja, P. Transethosomes of econazole nitrate for transdermal delivery: Development, in-vitro characterization, and ex-vivo assessment. Pharm. Nanotechnol. 2018, 6, 171-179. [CrossRef]

44. El Maghraby, G.M.; Williams, A.C. Vesicular systems for delivering conventional small organic molecules and larger macromolecules to and through human skin. Expert Opin. Drug Deliv. 2009, 6, 149-163. [CrossRef] [PubMed]

45. Goyal, M.K.; Qureshi, J. Formulation and evaluation of itraconazole niosomal gel for topical application. J. Drug Deliv. Ther. 2019, 9, 961-966.

46. Kumar, A.; Dua, J.S. Formulation and evaluation of itraconazole niosomal gel. Asian J. Pharm. Res. Devel. 2018, 6, 76-80. [CrossRef]

47. Shirsand, S.; Para, M.; Nagendrakumar, D.; Kanani, K.; Keerthy, D. Formulation and evaluation of Ketoconazole niosomal gel drug delivery system. Int. J. Pharm. Investig. 2012, 2, 201-207. [CrossRef] [PubMed]

48. Abu El-Enin, A.S.M.; Khalifa, M.K.A.; Dawaba, A.M.; Dawaba, H.M. Proniosomal gel-mediated topical delivery of fluconazole: Development, in vitro characterization, and microbiological evaluation. J. Adv. Pharm. Technol. Res. 2019, 10, 20-26. [CrossRef]

49. El-Ridy, M.S.; Abdelbary, A.; Essam, T.; El-Salam, R.M.A.; Kassem, A.A.A. Niosomes as a potential drug delivery system for increasing the efficacy and safety of nystatin. Drug Dev. Ind. Pharm. 2011, 37, 1491-1508. [CrossRef]

50. Kakkar, S.; Kaur, I.P. Spanlastics-A novel nanovesicular carrier system for ocular delivery. Int. J. Pharm. 2011, 413, 202-210. [CrossRef] [PubMed]

51. Kaur, I.P.; Rana, C.; Singh, M.; Bhushan, S.; Singh, H.; Kakkar, S. Development and evaluation of novel surfactant-based elastic vesicular system for ocular delivery of fluconazole. J. Ocul. Pharmacol. Ther. 2012, 28, 484-496. [CrossRef] [PubMed]

52. Karami, Z.; Hamidi, M. Cubosomes: Remarkable drug delivery potential. Drug Discov. Today 2016, 21, 789-801. [CrossRef] 
53. El-Meshad, A.N.; Mohsen, A.M. Enhanced corneal permeation and antimycotic activity of itraconazole against Candida albicans via a novel nanosystem vesicle. Drug Deliv. 2016, 23, 2115-2123. [CrossRef]

54. Basha, M.; Abd El-Alim, S.H.; Shamma, R.N.; Awad, G.E.A. Design and optimization of surfactant-based nanovesicles for ocular delivery of Clotrimazole. J. Liposome Res. 2013, 23, 203-210. [CrossRef] [PubMed]

55. Ing, L.Y.; Zin, N.M.; Sarwar, A.; Katas, H. Antifungal activity of chitosan nanoparticles and correlation with their physical properties. Int. J. Biomater. 2012, 2012, 632698. [CrossRef] [PubMed]

56. Divya, K.; Smitha, V.; Jisha, M.S. Antifungal, antioxidant and cytotoxic activities of chitosan nanoparticles and its use as an edible coating on vegetables. Int. J. Biol. Macromol. 2018, 114, 572-577. [CrossRef] [PubMed]

57. Ling, X.; Huang, Z.; Wang, J.; Xie, J.; Feng, M.; Chen, Y.; Abbas, F.; Tu, J.; Wu, J.; Sun, C. Development of an itraconazole encapsulated polymeric nanoparticle platform for effective antifungal therapy. J. Mater. Chem. B Mater. Biol. Med. 2016, 4, 1787-1796. [CrossRef]

58. Arciniegas-Grijalba, P.A.; Patiño-Portela, M.C.; Mosquera-Sánchez, L.P.; Guerrero-Vargas, J.A.; Rodríguez-Páez, J.E. ZnO nanoparticles (ZnO-NPs) and their antifungal activity against coffee fungus Erythricium salmonicolor. Appl. Nanosci. 2017, 7, 225-241. [CrossRef]

59. Sawai, J.; Yoshikawa, T. Quantitative evaluation of antifungal activity of metallic oxide powders $(\mathrm{MgO}, \mathrm{CaO}$ and $\mathrm{ZnO})$ by an indirect conductimetric assay. J. Appl. Microbiol. 2004, 96, 803-809. [CrossRef]

60. Gutiérrez, J.A.; Caballero, S.; Díaz, L.A.; Guerrero, M.A.; Ruiz, J.; Ortiz, C.C. High antifungal activity against candida species of monometallic and bimetallic nanoparticles synthesized in nanoreactors. ACS Biomater. Sci. Eng. 2018, 4, 647-653. [CrossRef]

61. Pereira, L.; Dias, N.; Carvalho, J.; Fernandes, S.; Santos, C.; Lima, N. Synthesis, characterization and antifungal activity of chemically and fungal-produced silver nanoparticles against Trichophyton rubrum. J. Appl. Microbiol. 2014, 117, 1601-1613. [CrossRef]

62. Bocate, K.P.; Reis, G.F.; de Souza, P.C.; Oliveira Junior, A.G.; Durán, N.; Nakazato, G.; Furlaneto, M.C.; de Almeida, R.S.; Panagio, L.A. Antifungal activity of silver nanoparticles and simvastatin against toxigenic species of Aspergillus. Int. J. Food Microbiol. 2019, 291, 79-86. [CrossRef]

63. Nasrollahi, A.; Pourshamsian, K.H.; Mansourkiaee, P. Antifungal activity of silver nanoparticles on some of fungi. Int. J. Nano Dimens. 2011, 1, 233-239.

64. Mallmann, E.J.J.; Cunha, F.A.; Castro, B.N.M.F.; Maciel, A.M.; Menezes, E.A.; Fechine, P.B.A. Antifungal activity of silver nanoparticles obtained by green synthesis. Rev. Inst. Med. Trop. Sao Paulo 2015, 57, 165-167. [CrossRef]

65. Alananbeh, K.M.; Al-Refaee, W.J.; Al-Qodah, Z. Antifungal effect of silver nanoparticles on selected fungi isolated from raw and waste water. Indian J. Pharm. Sci. 2017, 79, 559-567. [CrossRef]

66. Mishra, V.; Nayak, P.; Singh, M.; Tambuwala, M.M.; Aljabali, A.A.; Chellappan, D.K.; Dua, K. Pharmaceutical aspects of green synthesized silver nanoparticles: A boon to cancer treatment. Anti-Cancer Agents Med. Chem. 2021, 21, 1490-1509. [CrossRef]

67. Zhang, Y.; Chen, Y.-Y.; Huang, L.; Chai, Z.-G.; Shen, L.-J.; Xiao, Y.-H. The antifungal effects and mechanical properties of silver bromide/cationic polymer nano-composite-modified Poly-methyl methacrylate-based dental resin. Sci. Rep. 2017, 7, 1547. [CrossRef] [PubMed]

68. Oliveira, D.R.B.; de Figueiredo Furtado, G.; Cunha, R.L. Solid lipid nanoparticles stabilized by sodium caseinate and lactoferrin. Food Hydrocoll. 2019, 90, 321-329. [CrossRef]

69. Mishra, V.; Bansal, K.K.; Verma, A.; Yadav, N.; Thakur, S.; Sudhakar, K.; Rosenholm, J.M. Solid lipid nanoparticles: Emerging colloidal nano drug delivery systems. Pharmaceutics 2018, 10, 191. [CrossRef] [PubMed]

70. Müller, R.H.; Radtke, M.; Wissing, S.A. Nanostructured lipid matrices for improved microencapsulation of drugs. Int. J. Pharm. 2002, 242, 121-128. [CrossRef]

71. El-Housiny, S.; Shams Eldeen, M.A.; El-Attar, Y.A.; Salem, H.A.; Attia, D.; Bendas, E.R.; El-Nabarawi, M.A. Fluconazole-loaded solid lipid nanoparticles topical gel for treatment of pityriasis versicolor: Formulation and clinical study. Drug Deliv. 2018, 25, 78-90. [CrossRef]

72. Jansook, P.; Pichayakorn, W.; Ritthidej, G.C. Amphotericin B-loaded solid lipid nanoparticles (SLNs) and nanostructured lipid carrier (NLCs): Effect of drug loading and biopharmaceutical characterizations. Drug Dev. Ind. Pharm. 2018, 44, 1693-1700. [CrossRef] [PubMed]

73. Gratieri, T.; Krawczyk-Santos, A.P.; da Rocha, P.B.; Gelfuso, G.M.; Marreto, R.N.; Taveira, S.F. SLN-and NLC-encapsulating antifungal agents: Skin drug delivery and their unexplored potential for treating onychomycosis. Curr. Pharm. Des. 2017, 23, 6684-6695. [CrossRef]

74. Souto, E.B.; Müller, R.H. The use of $\mathrm{SLN}^{\circledR}$ and $\mathrm{NLC}^{\circledR}$ as topical particulate carriers for imidazole antifungal agents. Die Pharm. 2006, 61, 431-437.

75. Jaiswal, M.; Dudhe, R.; Sharma, P.K. Nanoemulsion: An advanced mode of drug delivery system. 3 Biotech 2015, 5, 123-127. [CrossRef]

76. Yang, Q.; Liu, S.; Gu, Y.; Tang, X.; Wang, T.; Wu, J.; Liu, J. Development of sulconazole-loaded nanoemulsions for enhancement of transdermal permeation and antifungal activity. Int. J. Nanomed. 2019, 14, 3955-3966. [CrossRef]

77. Garcia, A.; Fan, Y.Y.; Vellanki, S.; Huh, E.Y.; Vanegas, D.; Wang, S.H.; Lee, S.C. Nanoemulsion as an effective treatment against human-pathogenic fungi. mSphere 2019, 4. [CrossRef] [PubMed] 
78. Wu, W.; Wieckowski, S.; Pastorin, G.; Benincasa, M.; Klumpp, C.; Briand, J.-P.; Gennaro, R.; Prato, M.; Bianco, A. Targeted delivery of amphotericin B to cells by using functionalized carbon nanotubes. Angew. Chem. Int. Ed. Engl. 2005, 44, 6358-6362. [CrossRef]

79. Benincasa, M.; Pacor, S.; Wu, W.; Prato, M.; Bianco, A.; Gennaro, R. Antifungal activity of amphotericin B conjugated to carbon nanotubes. ACS Nano 2011, 5, 199-208. [CrossRef] [PubMed]

80. Liu, R.; Chen, Y.; Ma, Q.; Luo, J.; Wei, W.; Liu, X. Noncovalent functionalization of carbon nanotube using poly (vinylcarbazole)based compatibilizer for reinforcement and conductivity improvement in epoxy composite. J. Appl. Polym. Sci. 2017, 134. [CrossRef]

81. Rostamizadeh, K.; Habibizadeh, M.; Dalali, N.; Ramazani, A. Preparation and characterization of PEGylated multiwall carbon nanotubes as covalently conjugated and non-covalent drug carrier: A comparative study. Mater. Sci. Eng. C Mater. Biol. Appl. 2017, 74, 1-9. [CrossRef]

82. Mishra, V.; Kesharwani, P.; Jain, N.K. Biomedical applications and toxicological aspects of functionalized carbon nanotubes. Crit. Rev. Ther. Drug Carr. Syst. 2018, 35, 293-330. [CrossRef]

83. Zare, H.; Ahmadi, S.; Ghasemi, A.; Ghanbari, M.; Rabiee, N.; Bagherzadeh, M.; Karimi, M.; Webster, T.J.; Hamblin, M.R.; Mostafavi, E. Carbon nanotubes: Smart drug/gene delivery carriers. Int. J. Nanomed. 2021, 16, 1681. [CrossRef] [PubMed]

84. Wani, T.U.; Mohi-Ud-Din, R.; Wani, T.A.; Mir, R.H.; Itoo, A.M.; Sheikh, F.A.; Khan, N.A.; Pottoo, F.H. Green synthesis, spectroscopic characterization and biomedical applications of carbon nanotubes. Curr. Pharm. Biotechnol. 2021, 22, 793-807. [CrossRef]

85. Mishra, V.; Singh, M.; Nayak, P.; Sriram, P.; Suttee, A. Carbon nanotubes as emerging nanocarriers in drug delivery: An overview. Int. J. Pharm. Qual. Assur. 2020, 11, 373-378.

86. Shakoor, S.; Sun, L.; Wang, D. Multi-walled carbon nanotubes enhanced fungal colonization and suppressed innate immune response to fungal infection in nematodes. Toxicol. Res. 2016, 5, 492-499. [CrossRef] [PubMed]

87. Vikelouda, A.; Simitsopoulou, M.; Kechagioglou, P.; Papi, R.; Kyriakidis, D.; Roilides, E. Antifungal activity of functionalized carbon nanotubes conjugated to Amphotericin-B against Candida albicans and Candida parapsilosis biofilms. Mycoses 2017, $60,85$.

88. Wang, X.; Zhou, Z.; Chen, F. Surface modification of carbon nanotubes with an enhanced antifungal activity for the control of plant fungal pathogen. Materials 2017, 10, 1375. [CrossRef]

89. Pieńko, T.; Grudzień, M.; Taciak, P.P.; Mazurek, A.P. Adsorption of antifungal drugs inside pristine and functionalized fullerenes and nanotubes: DFT investigation. Curr. Comput. Aided Drug Des. 2017, 13, 177-185. [CrossRef]

90. Saluja, V.; Mishra, Y.; Mishra, V.; Giri, N.; Nayak, P. Dendrimers based cancer nanotheranostics: An overview. Int. J. Pharm. 2021, 120485. [CrossRef] [PubMed]

91. Saluja, V.; Mankoo, A.; Saraogi, G.K.; Tambuwala, M.M.; Mishra, V. Smart dendrimers: Synergizing the targeting of anticancer bioactives. J. Drug Deliv. Sci. Technol. 2019, 52, 15-26. [CrossRef]

92. Mishra, V.; Yadav, N.; Saraogi, G.K.; Tambuwala, M.M.; Giri, N. Dendrimer based nanoarchitectures in diabetes management: An overview. Curr. Pharm. Des. 2019, 25, 2569-2583. [CrossRef]

93. Mishra, V.; Gupta, U.; Jain, N.K. Surface-engineered dendrimers: A solution for toxicity issues. J. Biomater. Sci. Polym. Ed. 2009, 20, 141-166. [CrossRef]

94. Svenson, S.; Tomalia, D.A. Dendrimers in biomedical applications-Reflections on the field. Adv. Drug Deliv. Rev. 2012, 64, 102-115. [CrossRef]

95. Lazniewska, J.; Milowska, K.; Gabryelak, T. Dendrimers-Revolutionary drugs for infectious diseases. Wiley Interdiscip. Rev. Nanomed. Nanobiotechnol. 2012, 4, 469-491. [CrossRef]

96. Winnicka, K.; Sosnowska, K.; Wieczorek, P.; Sacha, P.T.; Tryniszewska, E. Poly(amidoamine) dendrimers increase antifungal activity of clotrimazole. Biol. Pharm. Bull. 2011, 34, 1129-1133. [CrossRef]

97. Gupta, U.; Agashe, H.B.; Jain, N.K. Polypropylene imine dendrimer mediated solubility enhancement: Effect of $\mathrm{pH}$ and functional groups of hydrophobes. J. Pharm. Pharm. Sci. 2007, 10, 358-367.

98. Janiszewska, J.; Sowińska, M.; Rajnisz, A.; Solecka, J.; Łącka, I.; Milewski, S.; Urbańczyk-Lipkowska, Z. Novel dendrimeric lipopeptides with antifungal activity. Bioorg. Med. Chem. Lett. 2012, 22, 1388-1393. [CrossRef]

99. Zielińska, P.; Staniszewska, M.; Bondaryk, M.; Koronkiewicz, M.; Urbańczyk-Lipkowska, Z. Design and studies of multiple mechanism of anti-Candida activity of a new potent Trp-rich peptide dendrimers. Eur. J. Med. Chem. 2015, 105, 106-119. [CrossRef] [PubMed]

100. Winnicka, K.; Wroblewska, M.; Wieczorek, P.; Sacha, P.T.; Tryniszewska, E. Hydrogel of ketoconazole and PAMAM dendrimers: Formulation and antifungal activity. Molecules 2012, 17, 4612-4624. [CrossRef] [PubMed]

101. Khairnar, G.A.; Chavan-Patil, A.B.; Palve, P.R.; Bhise, S.B.; Mourya, V.K.; Kulkarni, C.G. Dendrimers: Potential tool for enhancement of antifungal activity. Int. J. Pharmtech. Res. 2010, 2, 736-739.

102. Kalvatala, S. Ongoing Challenges with the Safety and Toxicity of Nanoparticles in the Field of Medicine. In Smart Nanotechnology with Applications, 1st ed.; Bhargava, C., Sachdeva, A., Sharma, P.K., Eds.; CRC: Boca Raton, FL, USA, 2021; pp. 261-268.

103. Staniszewska, M.; Bondaryk, M.; Zielińska, P.; Urbańczyk-Lipkowska, Z. The in vitro effects of new D186 dendrimer on virulence factors of Candida albicans. J. Antibiot. 2014, 67, 425-432. [CrossRef]

104. Jose, J.; Charyulu, R.N. Prolonged drug delivery system of an antifungal drug by association with polyamidoamine dendrimers. Int. J. Pharm. Investig. 2016, 6, 123-127. [CrossRef] 
105. Mishra, V.; Gupta, U.; Jain, N.K. Influence of different generations of poly (propylene imine) dendrimers on human erythrocytes. Pharmazie 2010, 65, 891-895. [PubMed]

106. Venuganti, V.V.K.; Perumal, O.P. Poly(amidoamine) dendrimers as skin penetration enhancers: Influence of charge, generation, and concentration. J. Pharm. Sci. 2009, 98, 2345-2356. [CrossRef]

107. Yang, Y.; Sunoqrot, S.; Stowell, C.; Ji, J.; Lee, C.-W.; Kim, J.W.; Khan, S.A.; Hong, S. Effect of size, surface charge, and hydrophobicity of poly(amidoamine) dendrimers on their skin penetration. Biomacromolecules 2012, 13, 2154-2162. [CrossRef]

108. Nogueira, S.S.; de Araujo-Nobre, A.R.; Mafud, A.C.; Guimarães, M.A.; Alves, M.M.M.; Plácido, A.; Carvalho, F.A.A.; Arcanjo, D.D.R.; Mascarenhas, Y.; Costa, F.G.; et al. Silver nanoparticle stabilized by hydrolyzed collagen and natural polymers: Synthesis, characterization and antibacterial-antifungal evaluation. Int. J. Biol. Macromol. 2019, 135, 808-814. [CrossRef] [PubMed]

109. Perez, A.P.; Altube, M.J.; Schilrreff, P.; Apezteguia, G.; Celes, F.S.; Zacchino, S.; de Oliveira, C.I.; Romero, E.L.; Morilla, M.J. Topical amphotericin B in ultradeformable liposomes: Formulation, skin penetration study, antifungal and antileishmanial activity in vitro. Colloids Surf. B Biointerfaces 2016, 139, 190-198. [CrossRef] [PubMed] 